\title{
Accuracy of bone assessments for verifying age in adolescents - application in sport
}

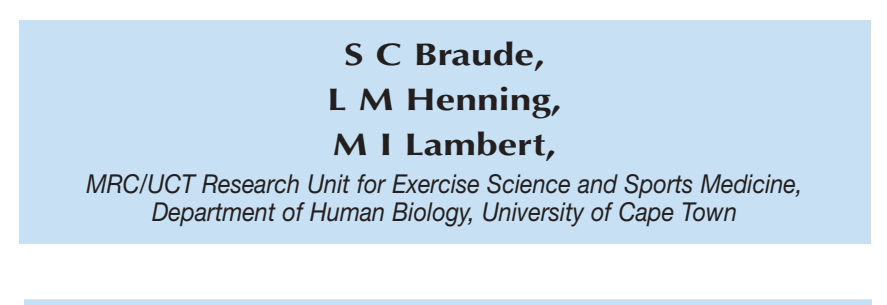

\begin{abstract}
Background. Cheating often occurs in sports that are defined by age when older participants compete by falsifying their true age. In some cases administrators have responded by implementing a programme that attempts to establish true age by measuring the skeletal age of competitors. However, because the technique has not been validated in this context there is a risk that competitors who are the correct age may have been unfairly excluded from competition based on these tests.

Objective. To determine whether this technique has sufficient precision to be used effectively to identify 'age cheats'.

Methods. Twenty-three males (14 - 18 years) volunteered for the study. Their skeletal age was determined by means of an X-ray assessment of the hand and wrist undertaken by nine experienced radiologists.

Results. The coefficient of variation of skeletal age for each subject predicted by the different radiologists ranged from $0 \%$ to $3.8 \%$. The average difference between the chronological and skeletal ages was -0.5 years ( $95 \%$ confidence interval: $-0.9--0.1$ years), with a maximum underprediction of 2.4 years and maximum over-prediction of 0.9 years. The magnitude of the error in the prediction did not seem to be related to either the mass or stature percentile of the subjects.

Conclusion. The technique of assessing skeletal age in an attempt to identify sports participants who are older than the prescribed age limit lacks the necessary precision. Until such time as an objective biological method is available to predict age more accurately, sport administrators should rather develop structures that can verify the accuracy of birth certificates.
\end{abstract}

\section{Introduction}

The incidence of age cheating in sport has increased and has caused a problem comparable to athletes taking illegal substances. ${ }^{1,2}$ For example, it has been alleged that the captain of the South African under-14 national soccer squad was a 17 -year-old student playing under a false name. ${ }^{3,4}$ Furthermore, more than half of this team that won the International Four Nations Tournament for underprivileged children in 1998 were over the age limit. ${ }^{5}$ Identity documents or birth certificates cannot be used with confidence to identify age, particularly in developing countries. In South Africa, soccer administrators responded to the age cheating by introducing skeletal age determinations at some of the major age-group tournaments ${ }^{6}$ in an attempt to identify players older than the prescribed age limit. They assessed the skeletal maturity of the players as they were under the impression that this technique was definitive and without error. Several players were excluded from tournaments for ostensibly being over-age, causing a reaction from many of the parents of these players who claimed that their children had been disqualified unfairly.

Skeletal maturity or bone age describes the degree of biological maturation. ${ }^{7}$ The most common method of skeletal maturity assessment uses a radiograph of the left hand and wrist to determine the different stages in bone maturation. ${ }^{8}$ There are two different techniques, namely the Tanner and Whitehouse II (TW2) ${ }^{9}$ and Greulich and Pyle ${ }^{10}$ methods. Both techniques have similar reproducibility ${ }^{8}$ and are used to predict either the adult height of a child or to evaluate advanced or delayed growth. The Greulich and Pyle method is faster and easier to score and it is often the preferred method for a clinical application. ${ }^{8}$ However there are no data on the precision of this technique in predicting age, particularly in a sporting context.

\section{Objective}

The aim of this study was to establish the reliability of determining chronological age in adolescent boys via hand and wrist X-rays using the Greulich and Pyle method. ${ }^{10}$ The goal was to determine whether this technique has a practical application in verifying chronological age of boys competing in specified age groups.

\section{Methods}

Twenty-three subjects between the ages of 14 and 18 years volunteered for the study. Written consent was provided by the parents after the study was explained. The study was approved by the University of Cape Town Research and Ethics Committee. All subjects had their age verified by official identity documents which were derived from original birth certificates. The stature and mass of each subject was measured to the nearest $\mathrm{cm}$ and $0.5 \mathrm{~kg}$ respectively. Each subject then reported to the same radiology practice and had an X-ray taken of their left hand and wrist measured in the anterior-posterior position. The X-rays were distributed to 9 independent, experienced radiologists who assessed the skeletal maturity and predicated chronological age from this X-ray using the Greulich and Pyle method. ${ }^{10}$ The radiologists were blinded to the identity and age of each subject.

The stature and mass of each subject was compared with normative data derived from a similar population of boys $(N=2167)$ (Sports Science Institute of South Africa - unpublished data). The percentiles for stature and mass were calculated for these data for the ages of the subjects in this study. 


\section{Statistics}

Data are expressed as mean \pm standard deviation (SD) or as $95 \%$ confidence intervals (CIs) where appropriate. The repeatability of the age predictions was determined using an analysis of variance with repeated measures. The coefficient of variation ((mean/standard deviation) x 100) of the age assessments by the 9 different radiologists was calculated for each subject. A Pearson's moment correlation coefficient was calculated to determine the relationship between chronological and skeletal age. The limits of agreement between these variables were calculated using the Bland-Altman test. ${ }^{11}$ Statistical significance was accepted as $p<$ 0.05 .

\section{Results}

General characteristics of all 23 subjects are shown in Table I. The average body mass was $64.6 \pm 14.4 \mathrm{~kg}$, with a range from 39.9 to $96.4 \mathrm{~kg}$. The mass percentile ranged from $9 \%$ to $97 \%$. Stature varied from $150.0 \mathrm{~cm}$ to $186.0 \mathrm{~cm}$, with an average of $173.6 \pm 8.9 \mathrm{~cm}$. The stature percentiles ranged from $5 \%$ to $99 \%$. The chronological ages of the subjects ranged from 14.1 to 17.9 years $(15.7 \pm 1.2$ years). The skeletal age of each subject determined from the scores of 9 independent radiologists are shown in Table I with their 95\% CIs. The coefficient of variation of skeletal age for each subject predicted by the 9 different radiologists ranged from $0 \%$ to $3.8 \%$ (mean \pm SD $2.1 \pm 1.0 \%$ ). The average difference between the chronological and skeletal ages was -0.5 years ( $95 \%$ CI: -0.9 to -0.1 years) with a maximum underprediction of 2.4 years and maximum overprediction of 0.9 years. The relationship between the chronological age and skeletal age (average of the 9 scores) was $r=0.71(p<0.0001)$.

The mean difference between chronological and skeletal age for each subject is plotted against mass percentile (a) and stature percentile (b) (Fig. 1). Negative deviations show an underestimation of the chronological age whereas a positive deviation shows an overestimation. The limits of agreement between chronological age and skeletal age were -2.4 - 1.4 years. There was no obvious systematic bias in predicting skeletal age related to either mass or stature percentiles (Fig. 2).

\section{Discussion}

Our main finding showed that the coefficient of variation of skeletal age for each subject predicted by the 9 different radiologists ranged from $0 \%$ to $3.8 \%$. This was not dependent on either the mass or the stature percentile of the subject. The mean difference between chronological and skeletal age for all the subjects was -0.5 years (95\% CI: $-0.9--0.1$ years) which defines the precision with which this type of test can be interpreted. In 1 subject the difference between the chronological age was underestimated by 2.4 years (Fig. 1). Clearly the method lacks the level of precision required for the purpose of screening players at agegroup tournaments where a player 1 day older than the defined age is regarded as 'too old' for the competition.

In a similar study on Dutch children $(N=572)$ the chronological age preceded skeletal age by 1.7 months in girls and 3.3 months in boys. ${ }^{12}$ In that study only 2 assessors were used, which may have contributed to the increased precision of their data compared with the data in our study where 9 assessors were used. The Greulich and Pyle method ${ }^{10}$ was developed on white children from England and should be used with reservation for children of different ethnicities. ${ }^{13}$ For example, prepu-

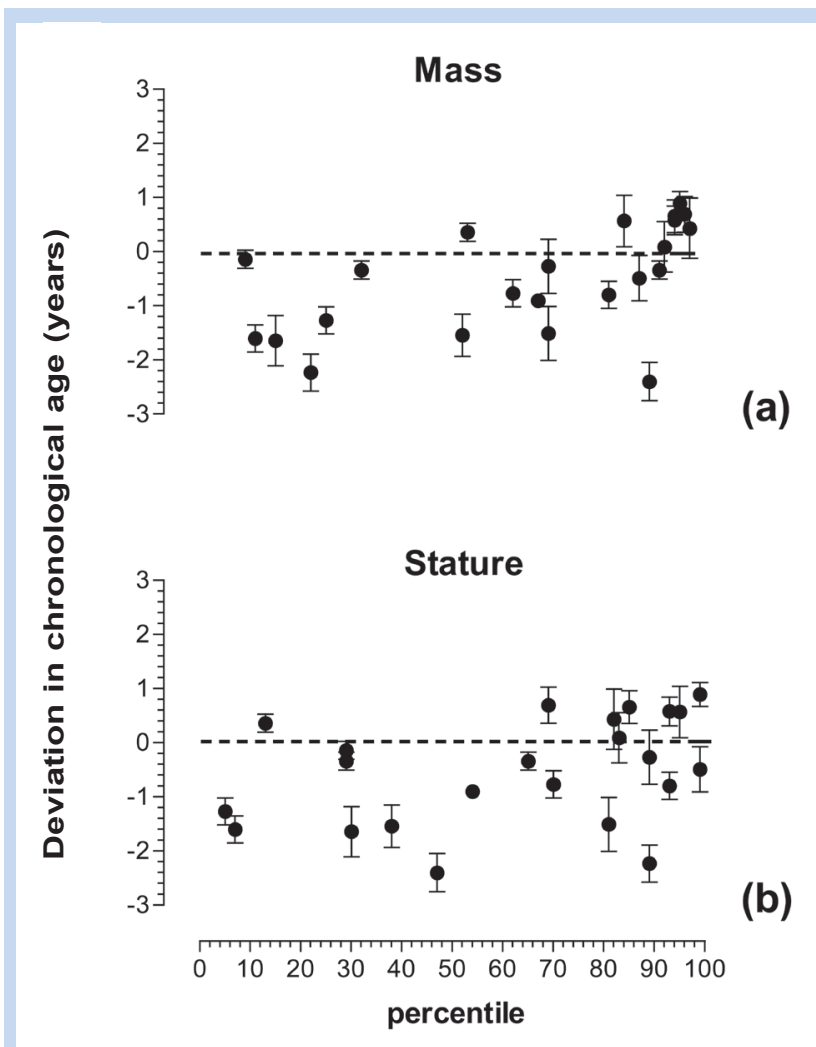

Fig. 1. Relationship between the deviations between chronological age and skeletal age and percentiles for body mass (a) and stature (b). A negative value means that chronological age has been underestimated by skeletal age. Each data point represents the mean difference for each subject $(\mathrm{N}=$ 23) with the standard deviations for the predictions of the 9 radiologists.

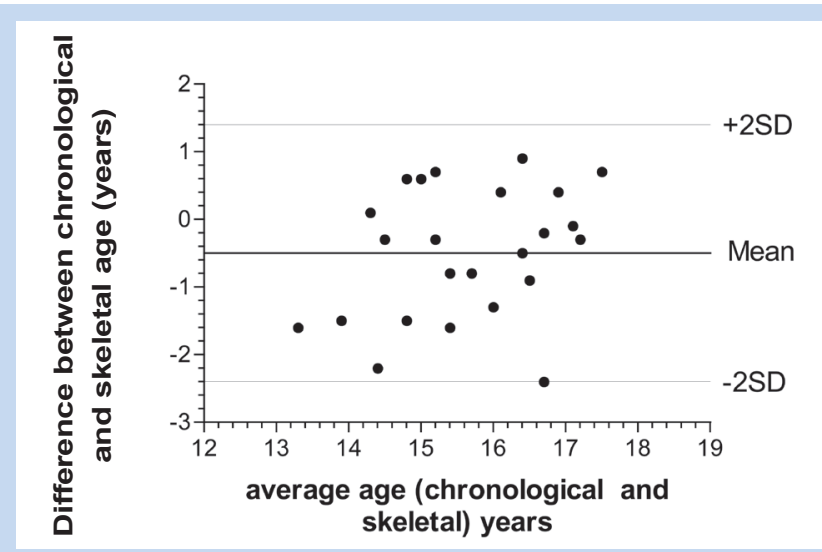

Fig. 2. The Bland-Altman plot ${ }^{11}$ for chronological and skeletal age. The limits of agreement were -2.4 to 1.4 years (negative differences mean that chronological age was underestimated).

bertal American children of European descent have significantly delayed skeletal maturation when compared with those of African descent, and postpubertal American children of European descent have significantly advanced skeletal maturation when compared with postpubertal children of African descent. ${ }^{14}$ Another factor affecting the accuracy of the assessment of skeletal age is the experience of the assessors. ${ }^{15}$ In that study 4 radiologists ( 2 experienced paediatric radiologists and 2 radiology residents) measured the skeletal age of 47 children (2 months 
ORIGINAL ARTICLE

\begin{tabular}{|c|c|c|c|c|c|c|c|}
\hline Subject & $\begin{array}{l}\text { Mass } \\
(\mathrm{kg})\end{array}$ & $\begin{array}{c}\text { Mass percentile } \\
(\%)\end{array}$ & $\begin{array}{l}\text { Stature } \\
(\mathrm{cm})\end{array}$ & $\begin{array}{l}\text { Stature percentile } \\
\text { (\%) }\end{array}$ & $\begin{array}{c}\text { BMI } \\
\left(\mathrm{kg} / \mathrm{m}^{2}\right)\end{array}$ & $\begin{array}{c}\text { Chronological } \\
\text { age (years) }\end{array}$ & $\begin{array}{c}\text { Skeletal age } 95 \% \\
\text { confidence intervals }\end{array}$ \\
\hline 1 & 82.0 & 91 & 181.0 & 65 & 25.0 & 17.4 & $16.9-17.2$ \\
\hline 2 & 96.4 & 96 & 175.0 & 69 & 31.5 & 17.2 & $17.6-18.1$ \\
\hline 3 & 77.4 & 95 & 182.0 & 99 & 23.4 & 16.0 & $16.7-17.1$ \\
\hline 4 & 47.2 & 15 & 164.0 & 30 & 17.5 & 16.2 & 14.2 - 14.9 \\
\hline 5 & 49.8 & 9 & 166.0 & 29 & 18.1 & 17.2 & $16.9-17.2$ \\
\hline 6 & 66.4 & 53 & 169.0 & 13 & 23.2 & 16.7 & $16.9-17.2$ \\
\hline 7 & 59.5 & 52 & 172.0 & 38 & 20.1 & 15.6 & $13.8-14.4$ \\
\hline 8 & 51.1 & 32 & 161.0 & 29 & 19.7 & 15.4 & $14.9-15.2$ \\
\hline 9 & 70.5 & 67 & 178.5 & 54 & 22.1 & 16.9 & $16.0-16.0$ \\
\hline 10 & 79.3 & 89 & 178.0 & 47 & 25.0 & 17.9 & $15.2-15.8$ \\
\hline 11 & 58.2 & 25 & 165.8 & 5 & 21.2 & 16.6 & $15.1-15.5$ \\
\hline 12 & 86.7 & 97 & 186.0 & 82 & 25.1 & 15.9 & $15.9-16.8$ \\
\hline 13 & 46.5 & 69 & 164.0 & 81 & 17.3 & 14.7 & $12.8-13.6$ \\
\hline 14 & 62.1 & 87 & 176.5 & 99 & 19.9 & 14.6 & $15.8-16.4$ \\
\hline 15 & 65.6 & 84 & 185.0 & 95 & 19.2 & 14.5 & $14.7-15.4$ \\
\hline 16 & 74.3 & 94 & 177.5 & 85 & 23.6 & 14.9 & $15.3-15.8$ \\
\hline 17 & 71.2 & 92 & 177.0 & 83 & 22.7 & 14.3 & $14.1-14.7$ \\
\hline 18 & 48.8 & 22 & 172.0 & 89 & 16.5 & 15.5 & $13.0-13.5$ \\
\hline 19 & 55.0 & 69 & 173.0 & 89 & 18.4 & 14.6 & $13.9-14.7$ \\
\hline 20 & 68.1 & 81 & 185.0 & 93 & 19.9 & 15.8 & $14.8-15.2$ \\
\hline 21 & 56.5 & 62 & 171.0 & 70 & 19.3 & 16.1 & $15.1-15.5$ \\
\hline 22 & 39.9 & 11 & 150.0 & 7 & 17.7 & 14.1 & $12.3-12.7$ \\
\hline 23 & 74.3 & 94 & 183.0 & 93 & 22.2 & 14.7 & $15.1-15.5$ \\
\hline Mean & 64.6 & 64.6 & 173.6 & 62.8 & 21.2 & 15.7 & $15.1-15.6$ \\
\hline$\pm \mathrm{SD}$ & \pm 14.4 & \pm 31.0 & \pm 8.9 & \pm 31.5 & \pm 3.5 & \pm 1.2 & \\
\hline
\end{tabular}

- 19 years). Although it was not significant, the difference between the chronological age and the measured bone age was $-1.5 \pm 7.6$ months for the experienced readers and $2.7 \pm 10.3$ months for the radiology residents. ${ }^{15}$ In our study all the radiologists were experienced and therefore the variation in the results cannot be attributed to this.

While determination of the skeletal age has important implications for forensic studies related to age determination in living people associated with crime, this is usually a part of a battery of tests including a general physical examination, X-rays of the skull, long bones and shoulder as well as an examination of the teeth by a dentist. ${ }^{16}$ Indeed, a combination of skeletal and orthodontic age variables provide a more accurate prediction of the chronological age than either method alone. ${ }^{17}$

In summary, verifying the age of participants in competitive sport defined by age groups is important. However, predicting skeletal age via hand and wrist X-ray using the Greulich and Pyle method in an attempt to verify chronological age lacks the precision needed and will result in many false-positive tests (i.e. saying someone is over-age when in fact they are not) or false-negative tests (i.e. failing to detect an over-age participant). Until accurate objective biological methods are available the authorities should rather implement structures that confirm the validity of birth certificates. 


\section{Conclusions}

Age cheats in sport are a reality, and strategies need to be implemented to identify players who are older than the prescribed age, and officials and parents who condone this behaviour. Whilst predicting age by measuring skeletal development has an important role to play in forensic and general medicine, the techniques do not have sufficient precision to be used in a sporting context where the accuracy has to be refined. At this stage, until a more accurate objective age-assessment technique is developed, it is recommended that officials implement strategies to verify birth certificates for the purpose of determining true age.

\section{Acknowledgements}

Thanks to Dr Michael Cooper and his team of radiologists who participated in assessing the skeletal age. Discovery Health, the Medical Research Council of South Africa and the Nellie Atkinson and Harry Crossley Research Funds of the University of Cape Town provided funding for the study.

1. Kwenaite T. Little cheats: who to blame? The Star, 26 August 1998. 2. Mokone T. Poverty no excuse for cheating. News24.com 2004 July 27.

3. Kwenaite T. South Africa national under-14. The Star, 29 August 1998.
4. Kwenaite T. SAFA to probe Amajita age cheats claims. Independent News Online, 28 February 2001 (www. iol.co.za).

5. Kwenaite T. SA's world champs' cheated' in France. The Star, 22 August 1998.

6. Motjuwadi H. X-rays expose soccer parents who cheat. Sunday Times, 4 October 1998

7. Beunen GP, Malina RM, Lefevre J, et al. Skeletal maturation, somatic growth and physical fitness in girls 6-16 years of age. Int J Sports Med 1997; 18:413-419.

8. King DG, Steventon DM, O'Sullivan MP, et al. Reproducibility of bone ages when performed by radiology registrars: an audit of Tanner and Whitehouse II versus Greulich and Pyle methods. Br J Radiol 1994; 67; 848-851.

9. Tanner JM, Whitehouse RH, Cameron N, Marshall WA, Healy MJR, Goldstein H. Assessment of Skeletal Maturity and Prediction of Adult Height (TW2 Method). 2nd ed. London: Academic Press, 1983.

10. Greulich WW, Pyle SI. Radiographic Atlas of Skeletal Development of the Hand and Wrist. 2nd ed. Stanford: Stanford University Press, 1959.

11. Bland JM, Altman DG. Statistical methods for assessing agreement between two methods of clinical measurement. Lancet 1986; 1:307-310.

12. van Rijn RR, Lequin MH, Robben SG, Hop WC, van Kuijk C. Is the Greulich and Pyle atlas still valid for Dutch Caucasian children today? Pediatr Radiol 2001; 31:748-752.

13. Ontell FK, Ivanovic M, Ablin DS, Barlow TW. Bone age in children of diverse ethnicity. Am J Roentgenol 1996; 167:1395-1398.

14. Mora S, Boechat MI, Pietka E, Huang HK, Gilsanz V. Skeletal age determinations in children of European and African descent: applicability of the Greulich and Pyle standards. Pediatr Res 2001; 50:624-628.

15. Groell R, Lindbichler F, Riepl T, Gherra L, Roposch A, Fotter R. The reliability of bone age determination in central European children using the Greulich and Pyle method. Br J Radiol 1999; 72:461-464.

16. Schmeling A, Olze A, Reisinger W, Rosing FW, Geserick G. Forensic age diagnostics of living individuals in criminal proceedings. Homo 2003; 54:162-169.

17. Garamendi PM, Landa MI, Ballesteros J, Solano MA. Reliability of the methods applied to assess age minority in living subjects around 18 years old. A survey on a Moroccan origin population. Forensic Sci Int 2005; 154(1): 3-12

\section{Clinical Doppler Ultrasound with CD-ROM, 2nd edition}
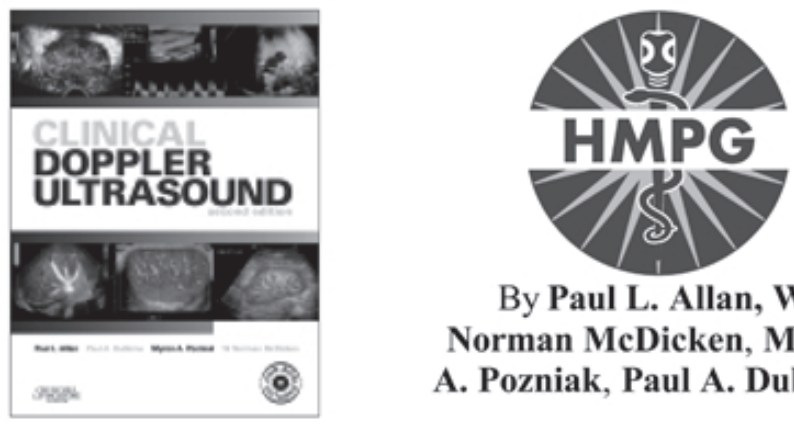

By Paul L. Allan, W.

Norman McDicken, Myron

A. Pozniak, Paul A. Dubbins,
To Order Contact: Health \& Medical Publishing Group Private Bag X1, Pinelands, 7430

Tel: $021-6578200$ Fax: 0866950461 e-mail: claudec@hmpg.co.za / brents@hmpg.co.za

\section{ISBN $0443101167 \cdot 384$ Pages $\cdot 610$ Illustrations} Churchill Livingstone · Published September 2006

Clinical Doppler Ultrasound is a unique, highly practical guide to those taking up Doppler techniques and who wish to obtain an understanding of the techniques, their major applications and their role in patient management. Beautifully illustrated in colour throughout, this is an essential introduction to the topic, written by experts in the field. Thoroughly updated to include the latest equipment and techniques, this is an ideal purchase for trainee radiologists with an interest in the topic, or consultants who wish to improve their technique. Vascular surgeons and vascular imaging technicians will also find the book useful. Included with the new edition is a free CD-Rom containing real-time clips of Doppler imaging to further illustrate and complement the concepts discussed in the book. 